\title{
Towards a Model To Predict Macular Dichromats' Naming Errors: Effects of CIE Saturation and Dichromatism Type
}

\author{
Julio Lillo, Isaac Vitini, Aurora Caballero, and Humberto Moreira \\ Complutense University of Madrid
}

Thirty macular dichromat children (12 protanopes +18 deuteranopes) and 29 controls, between 5 and 9 years old, participated in a monolexemic denomination task. Their clinical status was determincd after a repeated application of a chromatic test set (Ishilara, CUCVT, and TIDA). The stimuli to be named werc 12 tiles from the Color-Aid set belonging to the green, blue, and purple basic categories. Results showed that: (a) Dichromats made nore naming errors when low saturation stimuli were used; (b) protanopes made more errors that deuterinopes; and (c) pscudoisochromatic lines predicted accurately the type of most frequent naming errors but they underestimated macular dichromats' functional capacity to name colors. Results are consistent with a model of macular dichromats' vision that hypothesizes a residual third type of conc in the periphery of the retina. Implications of this fact for everyday use of colors by macular dichromats' and for the validity of standard clinical diagnoses are discussed.

Key words: color blindhess, color categorization, clinical diagnosis, dichromatism

Treinta niños dicromáticos maculares (12 protanopes +18 deuteranopes) y 29 controles, con edades comprendidas entre los 5 y 9 años, participaron en una tarea monolexémica de denominación de colores. Su categoría clínica se estableció partiendo de los resultados obtenidos tras la doble aplicación de una bateria de tests cromáticos (Ishihara, CUCVT y TIDA). Los estímulos a nombrar fueron doce muestras del conjunto del Color-Aid, pertenecientes a las categorias básicas verde, azul y morado. Los resultados mostraron que: (a) los dicromáticos tuvieron más errores cuando se utilizaron estímulos de baja saturación; (b) los protanopes cometieron más errores que los deuteranopes; (c) las lineas de pseudoisocromaticidad fueron adecuadas para predecir cuáles fueron los errores de nombramiento más frecuentes, pero fueron menos eficaces de lo esperado a la hora de predecir la capacidad funcional de los dicromáticos maculares en el nombramiento de colores. Los resultados concuerdan con un modelo de la visión de los dicromáticos maculares que asume la existencia en la periferia de un tercer tipo de cono. Se discuten las implicaciones de este hecho para comprender el uso cotidiano que hacen estos observadores de los colores y la validez del procedimiento habitual de diagnóstico clínico. Palabras clave: ceguera a los colores, categorización cromática, diagnóstico clinico, dicromatismo

Address correspondence to: Julio Lillo Jover, Dpto. Psicología Diferencial y del Trabajo. Facultad de Psicología. Universidad Complutense de Madrid. Campus de Somosaguas. 28023 Madrid (Spain). Fax: 91-3943189. E-mail: julillo@psi.ucm,es 
Color is not a property of objects or surfaces, but an attribute of the perceptual response produced by the brain as a result of the light that hits the retina. As the phenomenon of metamer colors show, in order to produce the perception of the same chromatic experience, two stimuli need not be physically identical, but only need to produce the same response pattern in the three cone types.

People with only two cone types in the macular retina are diagnosed as dichtomats (Fletcher \& Voke, 1985). When, as in red-green pathologies (daltonisms), the affected cone is the protoconc (the most sensitive to long wavelengths) or the deuteracone (most sensitive to medium wavelengths), a specific diagnosis of protanopia or deuteranopia, respectively, is made.

As protanopes and deuteranopes have only two types of cone, they have more metamers than common trichromats. Moreover, it is casy to indicate which stimuli will be metamers for dichromats but not for common trichromats: those (pseudoisochrornatic stmuli) that the common observer only differentiates using the cone type that the dichromat docs not possess. As we will sec, CIEu'v' chromacity diagram provides an easy way of identifying pseudoisochromalic stimuli.

Figure 1 shows the chromaticity diagram established by the Commission Internationale de l'Eclairage (CIE) in 1976. To the right, a black triangle $\left(u^{\prime}=0.65 ; v^{\prime}=0.50\right)$ shows the protanope convergence point in the position determined by Pitt in 1935 (this position is the one usually reproduced in the litcrature; see, for example, Fletcher \& Voke, 1985,

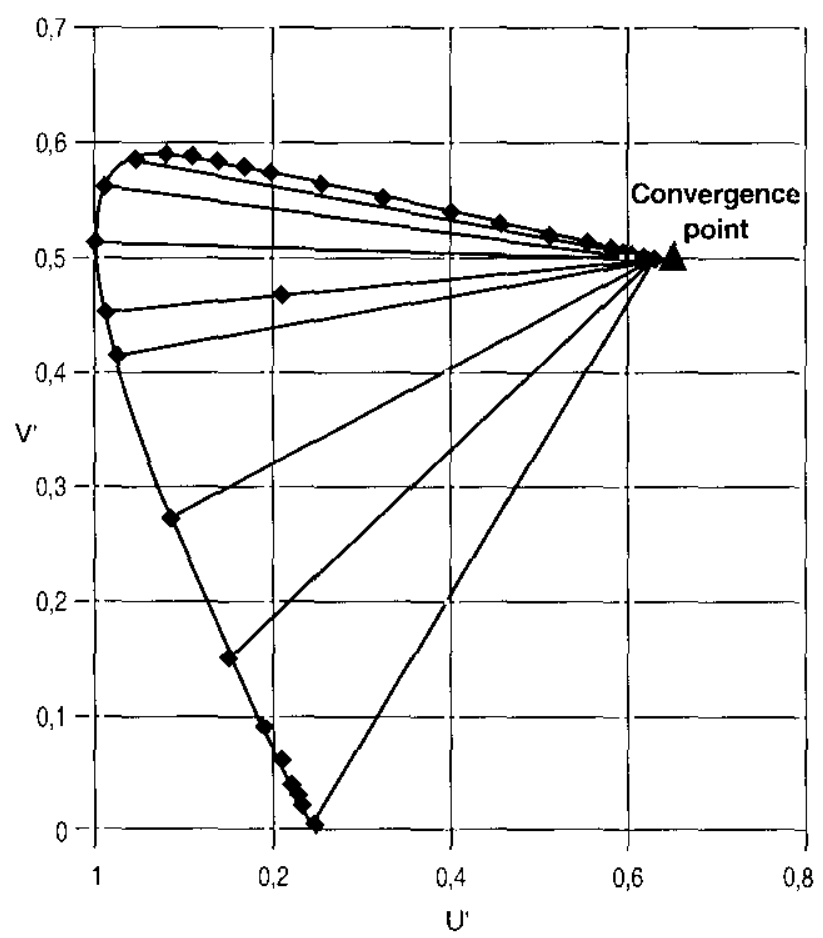

Figure /. ClEu'v' chromatic diagram and pseudoisochromatic lines. All stimuli that can be represented on the same pseudoisochromatic line are metamers for protanopes. p. 159; Birch, 1993, p. 37), and corresponds to an imaginary stimulus that only activates the protocones. Given the convergence point, protanope pseudoisochromatic stimuli can be determined in the following way:

(1) A pseudochromatic line can be determined by two points, the convergence point and the point corresponding to a specific color (for example, an achromatic color).

(2) Perfect metamerism is foreseen when two stimuli are presented on the same pseudochromatic line and are of equivalent reflectances.

(3) Smith and Pokorny's cone function fundamentals can be used to establish the reflectances for protanopes and deuteranopes. If we know the standard rellectance and the chromaticiy coordinates corresponding to a specific stimulus (for example, $R=22.6 ; x=0.269 ; y=442$ ), matrix algebra may be used (for example, Travis, 1991, chap. 3; Lillo, 2000 , chap. 7) to estimate the magnitude of the relative response (from zero to 100 ) that the stimulus produces in protocones (20.92) and deuteracones (25.93). The value of the former indicates the rellectance corresponding to deuteranopes, whereas that of the latter corresponds to protanopes.

\section{Basic Colors and CIExy Chromaticity Diagram: Model 1 Predictions}

CIE colorimetric measurements offer an objective way to determine which stimuli should be similar for normal trichromats (the ones with the same chromatic coordinates), and for dichromats (the ones with coordinates in the same pseudochromatic lines). They also provide information about some psychophysical properties, such as the dominant wavelength $\left(\lambda_{D}\right)$ or the CIE saturation (Su'v'- sce Hunt, 1987; Lillo, 2000 for a detailed description). However, they do not offer direct information about the way that color names are used in colloquial language.

Several methods can be used to decide when a word (such as yellow or green) corresponds to a basic chromatic category (Corbet \& Davics, 1997; Crawford, 1982). Some studies (Kay \& McDaniel, 1978) have shown that in Berlin and Kay's (1969) level-6 languages (such as English or Spanish), there are 11 basic categories: red, green, yellow, blue, orange, purple, pink, brown, white, black, and gray. Exlensive research carried out at the University of California (Boynton \& Olson, 1987, 1990; see also Sturges \& Whitfield, 1997), while providing additional information confirming the basic character of the eleven catcgories in English, also obtained results that can be used to specify the volumes occupied by every basic category in CIE spaces. More specifically, using the stimuli of the Optical Society of America (OSA) Atlas that received the same denomination by, at least, Cour of the seven participants in the Boynton and Olson (1987) naming task, we determined these volumes as is specifjed in Table 1 . 
Table 1

Chronatic (Dominam Wavelength and Saturation) and Reflestance Ranges for each Basic Catogory

\begin{tabular}{|c|c|c|c|c|c|c|}
\hline \multirow[t]{2}{*}{ Category } & \multicolumn{2}{|c|}{$\begin{array}{l}\text { Range Dominant } \\
\text { Wavelengths } \\
\text { (in } \mathrm{nm})\end{array}$} & \multirow[t]{2}{*}{ Saturation Range (CIFu'v') } & \multicolumn{3}{|c|}{ Reflectante Range } \\
\hline & & & & Standard & J'rotanope & Deuteranope \\
\hline Red & 610.5 & -496.5 & Partial (1.14-2.14) & $4.73-17.28$ & $3.44 \cdots 13.11$ & $5.56-\cdots 19.94$ \\
\hline Green & 494.0 & $-\quad 575.5$ & All except very neat $(0.28-1.25)$ & $3.94-65.89$ & $4.17-66.18$ & $3.79-65.70$ \\
\hline Yellow & 572.5 & $-\quad 585.5$ & All except very near $(0.43-1.25)$ & $27.51-74.93$ & $25.06-73.22$ & $28.74-76.03$ \\
\hline Bluc & 476.0 & -495.5 & All except very near $(0.34-1.66)$ & $3.30-61.83$ & $3.78-67.74$ & $3.00-58.05$ \\
\hline Orange & 586.5 & -614.0 & Partial $(0.92-2.45)$ & $12.74-6.3 .50$ & $9.12-43.89$ & $15.06-76.03$ \\
\hline Purple & -529.0 & -472.5 & All except very near $(0.26-1.42)$ & $3.51-32.05$ & $3.50-31.78$ & $3.51-32.23$ \\
\hline Pink & 598.0 & --555.0 & Ali $(0.08-1.64)$ & $17.89-60.22$ & $1560-56.70$ & $19.30-62.47$ \\
\hline Brown & 579.5 & --503.5 & All $(0.14-1.60)$ & $3.77-20.23$ & $3.59 \quad \ldots \quad 19.20$ & $\begin{array}{lll}3.89 & -20.89\end{array}$ \\
\hline White & & $-\ldots$ & $0-0.08$ & $50-[00$ & $50 \quad \ldots \quad 100$ & $50-100$ \\
\hline Black & & - & (1)-0.08 & $0-15$ & $(1-15$ & $\begin{array}{lll}0 & \cdots & 15\end{array}$ \\
\hline Gray & & $\ldots$ & $0-0.08$ & $5.75-70.86$ & $5.75-70.86$ & $5.75-70.86$ \\
\hline
\end{tabular}

Note. Saturation values were computed according the slandard equation (see Hunt. 1987, p. 198: Wyssechi, 1986, pp, 9-57: Lilio. 2000. p. 169): $S=13 \sqrt{\left(u^{\prime}-u_{n}^{\prime}\right)^{2}-\left(v^{\prime}-v_{n}^{\prime}\right)^{2}}$

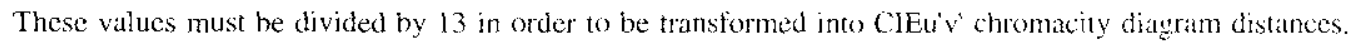

The first parameter to consider is the chromatic area. That is, the portion of CIE chromaticity diagram where stimuli belonging to a basic category are represented. To specify chromatic areas, Table I uses two parameters: (1) The range of dominant wavelengths and (2) the saturation range. For the latter parameter, the maximum values indicated correspond to the most saturated stimuli presented by the OSA Atlas.

Reflectance is the second parameter to consider for the delimitation of basic category volumes. In Table 1, three kinds of reflectances are specilied. The first is the standard one. The other two are transformations required to make predictions related to the use of basic categories by dichromats. As mentioned, transformations were carried out using the Smith and Pokorny (1975) fundamentals, so that the well known lightness alterations shown by dichromats are compensated for (see, for example, Hletcher \& Voke, 1985, pp. 167-169; Lillo, Collado, Vitini, Ponte, \& Sáncher, 1998).

Using the data from Table 1, the basic categories predicted by Model 1 as naming responses to a specific stimulus can be determined in the following way:

1. The coordinates of the stimulus and the convergence point are used to trace a pseudoisochromatic line.

2. There is chromatic concordance between the stimuius and a basic category when the pseudoisochromatic line intersects with the basic category chromatic area.

3. There is reflectance concordance when the stimulus is included in the range corresponding to a basic category.

4. A basic category will be a predicted response only when it has chromatic and reflectance concordance with the presented stimulus.
Figure 2 uses one of the tiles (green) employed in our research to provide a graphic example of the four steps we have just described. The (wo large squares with a plus sign inside indicate the positions of both stimuli required to trace protanopes pseudoisochromaticity line for the specific tile: the convergence point $\left(u^{\prime}=0.65 ; v^{\prime}=0.50\right)$ and the point corresponding to the target tile $\left(u^{\prime}=0.14 ; v^{\prime}=0.51\right)$. Larger round points indicate the tiles that were consistently catcgorized as red in Boynton and Olson's work (1987). Triangles. small griay squares, and small points provide the same kind of information for the orange, yellow, and green catcgories, respectively. Because the pseudoischromaticity line crosses the areas corresponding to these categories (which also occurs for gray, pink, and brown, but is not shown to avoid graphic contusion in the figure), these categories have chromatic concordance with that tile. Although tile standard reflectance is $22.6 \%$, the use of matrix algebra and the fundamentals of Smith and Pokorny (1975) provides a $25.93 \%$ protanope reflectance. As Table 1 indicated, this value falls within the ranges of transformed reflectance of the following categories: green (4.17-66.18), yellow (25.06$73.22)$, and orange $(9.12-43.89)$. Consequently, these categories fulfil the reflectance concordance requisitc. Table 1 also reveals that the red category does not fulfil this requisite because its reflectance range (3.44-13.11) does not include the $25.93 \%$ value.

Seemingly, there is a contradiction between our previous statement about the confusion between reds and greens being very common among color-blind people, and our subsequent statement about the green tile used as an example, where the red calegory did not fulfil the reflectance concordance requisite and, consequently, was not a predicted response 


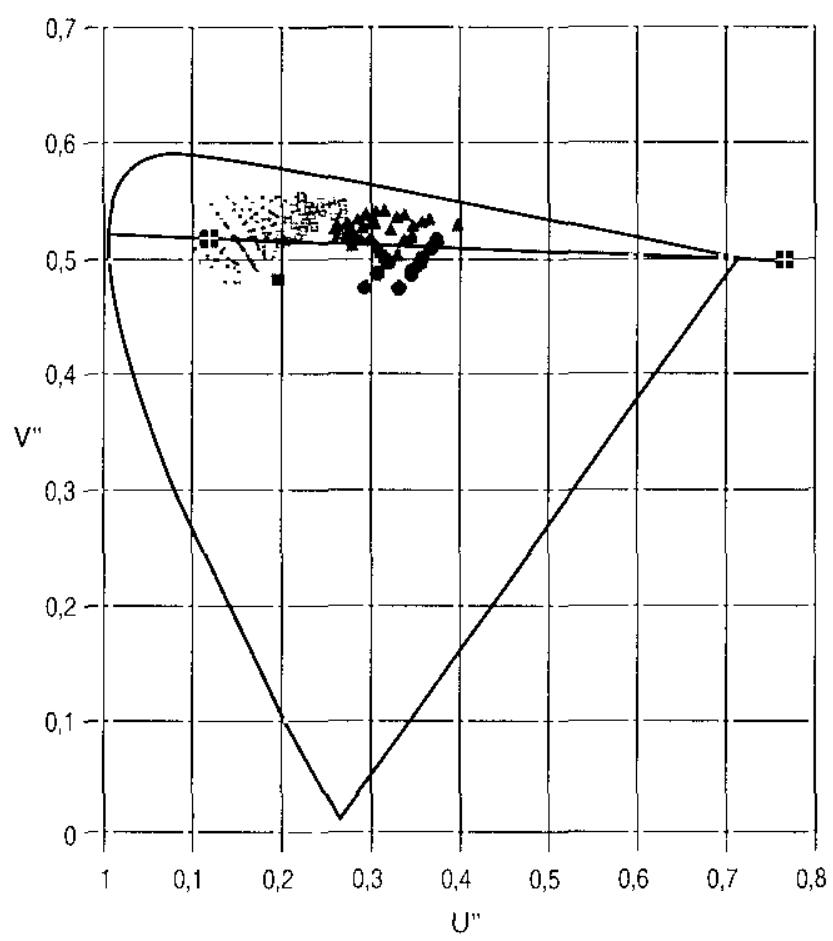

Figure 2. Chromatic concordance and pseudoisochromatic lines. Several chromatic areas are shown (1hick points = red; triangles $=$ orange: squares $=$ yell $(0 w ;$ small points $=$ green $)$. As these are crossed by the isochromatic line, the chromatic concordance requisite is fulfilied.

when presenting the target. However, there is no contradiction, considering that for some green tiles, the red category would be one of the expected responses: for the greens whose transformed reflectance is among the reflectances corresponding to the red category (3.44-13.11). In conclusion, Model 1 predicts that dark greens, but not medium or light greens, may be called reds by protanopes.

\section{Limitations of Model 1: Towards a new Predictive Model (Model 2)}

Model 1 would be accurate if, as wo have assumed till now, clinically diagnosed dichromats were real dichromats. The evidence we shali now comment on suggests that this assumption is not fully tenable.

At the turn of the century, Nagel (1904, cited in Fletcher \& Voke, 1985) designed the clinical anomaloscope which is still "the undisputed queen of all color vision test instruments" (Kaiser \& Boynton, 1996, p. 429). Nagel was aware that his anomaloscope projected onto a visual field restricted to the macula and, most important, he was the first (Nagel, 1905, as cited in Nagy, 1980 and in Nagy \& Boynton, 1979) to discover that most macular dichromats become anomalous trichromats when color stimulation strikes the peripheral retina. 'This discovery, however, was forgotten until it was finally rediscovered (Boynton \& Scheibner,
1967; Scheibner \& Boynton, 1968; Smith \& Pokorny, 1977).

Despite research suggesting that rods have some influence on macular dichromats' trichromaticity (Montag \& Boynton, 1987; Nagy, 1980; Smith \& Pokorny, 1977), this cannot be a full explanation of a phenomenon that appears when rods are saturated. In these circumstances, results obtained from high intensity Rayleigh matches (Nagy, 1980), selective adaptation (Scheibner \& Boynton, 1968), thuctuation colorimetry (Frome, Piantanida, \& Kelly, 1982) and color naming (Montag, 1994; Nagy \& Boynton, 1979) agree that macular dichromats have a third ype of cone, which is like an anomalous version of the cone that is absent in their macula.

The data described in this paper were obtained using a monolexemic color naming task and can be considered as an extension of previous work (Lillo, et al., in press; Montig, 1994: Montag \& Boynton, 1987) using the same task to study the trichromaticity of macular trichromats.

Adult dichromats participaled in the experiments of Montikg (1994; Montag \& Boynton, 1987), which allowed for systemalic evaluation of their denomination of the full set of surface colors contained in the OSA atlas with different presentation types. ClEu'v' centroids were computed for every basic category, allowing the author to conclude that: (a) Macular dichromats always exhibited a red-green compression in their responses; that is, their centroids were closer than those of common trichromats' for categories such as purple and blue, that are differentiated in terms of the red-greet response mechanism. (b) Macular dichromats' categorization was more similar to that of common observers" (normal trichromats) when relatively large (4 degrees instead of 1) and continuous (more than 2 seconds) stimuli were used.

The research by Lillo et al. (in press) can be considered as an extension of the work of Montag (1994), applied to children. As in Montag's experiments, this group of researchers used large stimuli and long exposure times in a naming task. In order to accommodate the experimental procedure to children, the number of participants was increased and a smaller stimulus sample was used. As the main target was to evaluate the way macular dichromat children use the eleven basic chromatic categories, a set of just 11 prototypes was used. The results led to the following conclusions: (a) Macular dichromats achicved almost 100 $\%$ correct responses when naming primary basic categories (red, green, yellow, and blue), but made signilicantly more crrors than controls when naming all the secondary chromatic categories (purple, orange, pink, brown); (b) Macular dichromats made fewer errors than predicted by Model 1 , although most errors were of the types predicted by the model; and (c) Protanopes tended to make more crrors than deuteranopes but, except for the pink prototype, these differences were not statistically significant.

Altogether, the studies by Montag (1994) and Lillo et al. (in press) suggest that in macular dichromats' periphera] retina, there are cones of a type similar to those missing 
from their macula. As with normal trichormats (Abramov, Gordon, \& Chan, 199I; Nagy \& Doyal, 1993), these cones must have a scattered distribution; therefore, they can only provide jnformation when continuous, saturated, and large stimuli are projected onto the periphery. In this case, the red-green opponent mechanism will give a diminished response (compared to that of common observers' macula) and macular dichromats' perception will be similar, but never identical, to that of common observers.

What will be called Model 2 from now on, is the result of assuming that in macular dichromats' peripheral retina, a cone type that is absent from macula is operating and. consequently, that these are anomalous trichromats when responding to large stimuli. From this model, the following predictions are made:

1. T'he identity of the erroneously employed basic categories can be predicted from the postulates of Model 1 (chromatic and reflectance concordance).

2. Due to the third cone availability, Model 2 predicts fewer naming errors than Model 1.

3. Due to the scattering of the cone distribution at periphery, it is assumed that, for macular dichromats, the third cone type has less informative capacity than that of common trictromats in their macula. Consequently, it is predicted that macular dicromats will produce more naming errors in response to low saturation stimuli, because in this situation, the third cone's activity will not be informative.

4. Considering the ample evidence (for example, Alpem \& Torii, 1968a, 1968b; Heath, 1958; Kinnear, 1986; Lillo et al., 1998; De Marco et al., 1992) about both the existence of lightness-perception alterations in macular dichromats, and how these alterations are more severe in protanopes than in deuteranopes, more naming errors are predicted for protanopes.

To evaluate the accuracy of Model 2, we selected a sample of 12 stimuli that, in previous pilot works, had received consistent naming responses by normal children. Specifically, the children named seven of these stimuli green. three of them blue, and two of them purple. Each category included at least one relatively high- and one relatively lowsaturation stimulus. The total number of stimuli was similar to the one used in previous research (Lillo et al., in press), and facilitutes administering the naming task to children. One of the stimuli contained in each of the three categories employed was its prototype. A relatively high number of green samples (seven) was included in the sample: (a) to confirm the surprisingly accurate results obtained in previous research (Lillo et al., in press); and (b) to increase the number of errors computed for every observer (otherwise, it would be not possible to obtain signilicant differences). As the category blue includes both dark and light stimuli, and these two types are categorized differently in some languages (see Davies \& Corbett, 1994), we used onc sample of light and another of dark blue.
Method

\section{Participants}

There were three groups of subjecls: protanopes $(n=$ 12), deuteranopes $(n=18)$, and controls $(n=29)$. Their mean age was 7.17 years $(S D=1.58)$. All of them lived in Alcorcón, a city near Madrid (Spain), and their mother tongue was Spanish. They were chosen from 1,631 boys, aged 5-9 years, who were screened for color-blindness.

\section{Materials}

The test battery consisted of the Ishihara Test (1917. see, for example, Birch, 1993, or Fletcher \& Voke, 1985. pp. 276-278), the City University Color Vision Test (CUCVT; Fletcher, 1980), and the "Test para Identificación de los Daltonismos" (TIDA ['Test to Identify ColorBlindness]; Lilio, 1996). A child was considered a dichromat if the following three critcria were met: (a) anomalous responses on more than $90 \%$ of the Ishihara tiles, (b) six or more out of ten red-green responses (protan or deutan responses) on the CUCVT, and (c) they were rated severe on the TIDA. Pilot work with adult observers showed that these are conservative criteria: All aduits meeting these criteria were confirmed as dichromats by the anomaloscope, although some adults diagnosed as dichromats by the anomaloscope failed to mect the triple criteria.

The classical Ishihara test uses a series of tiles on which certain numbers can be identified (e.g., "seven" or" "fortytwo"), provided the figures and the background on which they are presented are perceived as being of different colors. Given that some of the younger children had difficulties in identilying the two-ligure numbers verbally, they were allowed to emit their "number-response" figure-by-figure ("one and four" instead of fourteen). In some cases, morcover, children were allowed to trace with their finger the form of the number they said they recognized (if they were unable to identify it verbally).

The second of the tesis employed, the CUCVT, consists of 11 tiles ( 1 training +10 diagnostic), on which is presented a central reference pattern (a colored circle) and around it, four alternatives from which the children are asked to indicate (verbally or signaling with a finger) which is more similar to the central pattern. In alt of the diagnostic tiles, one of the allernatives corresponds to that which a person with normal chromatic vision would select, whereas the three remaining figures correspond to the three classic types of alteration ("protan," "deutan," and "tritan").

The TIDA is a test that employs pseudoisochromatic illustrations especially designed for children. It has two parts. The first part allows detecion of red-green colorvision anomalies (daltonisms) and starts the process of specific diagnosis. All the tiles show two groups of monkeys (3 larger ones on the top row and 4 smaller ones on the 
bottom row) with different functions. The function of the top-row monkeys is to act as reference clements for the type of stimuli the child should look for in the bottom row ("gray" or "colorless"). The function of the illustrations on the bottom row is to present the alternatives from which the child is requested to select those that he or she perceives as achromatic. The second part of the TIDA should only be administered to observers detected as color blind, and affords a specific red-green diagnosis. All tiles of this part show three monkeys to the children. Onc acts as reference. From the other two, the children are requested to select the most similat to the reference.

The stimuli for the color-naming lask consisted of twelve 5 -centimeter square colored tiles, presented on a neutral gray background. They projected a visual angle of $8^{\circ}$. The colors were from the Color-Aid range. Table 2 shows their Color-Aid identification (number and code), chromatic category, CIEu'v' chromaticity coordinates, dominant wavelength $\left(\lambda_{\Gamma}\right)$, standard (control) reflectance, and protanope and deutcranope reflectances. The basic colorimetric measurements $(\mathrm{Y}, \mathrm{x}, \mathrm{y})$ of the tiles were carried out with a Minolta CS-100 colorimeter. Starting with these measurements, all the parameters shown in Table 2 were computed. Specifically, to adequately compute the standard reflectance values, all the measurements with the colorimeter were carried out after fixing it onto a tripod and always pointing it at a spatial position that prevented the possible effects of specular reflection. First, a sample (N 0500), from the NCS color atlas (Hård, Sivick, \& Tonnquist, 1996) and of known rellectance ( $84.66 \%$ ), was placed in this position and its luminance (Y) was measured. From the same position, the tiles used as stimuli in the naming task were moasured successively, and the rellectance of a specific stimulus was deduced from the proportion between the luminances of the reference sample and the specific stimulus.

\section{Procedare}

Testing was carried out where possible using natural light with an illuminance level between 250-400 lux and a correlated color temperature between 4000-6500 Kelvin. These two parameters were measured with a Gossen Colormaster $3 \mathrm{~F}$ termocolorimeter. If light parameters fell outside of the desired values, natural light from the windows was mixed with light from a blue incandescent light bulb (its correlated color temperature was $3210 \mathrm{~K}$ ), from a conventional adjustable table lamp. Although no direct measurements of this parameter wore taken, in all cases, the CIE Color Rendering index values were very close to $100 \%$, as can be seen from the characteristics of the two kinds of light mixed (sce Hunt, 1987, chap. 5 and Appendix 7),

All children were tested individually in the color-naming lask. The tiles were shown one at a time, in random sequence. The tiles were viewed binocularly from a distance of approximately $35 \mathrm{~cm}$. The tester requested the child to respond with one color name, and no object names (such as banaha or tontato) were allowed.

Table 2

Stimuli dewription: Color-Aid Identification, Chmmatic Calegon, CIEuv' Chomaticity Coordinates and Saturation, Dominant Wavelength $\left(\lambda_{\mathrm{D}}\right)$, Standard (Control). Protanope, and Deuteranope Reflectances of the Tiles used in the Naming-Task

\begin{tabular}{|c|c|c|c|c|c|c|c|}
\hline Color-aid & $u^{\prime}$ & $v^{\prime}$ & $\begin{array}{l}\text { CIE } \\
\text { Sat }\end{array}$ & $\lambda_{13}$ & $\mathrm{R}$ & Rprot & Rdeut \\
\hline \multicolumn{8}{|l|}{ Greens } \\
\hline $36 \mathrm{Ygc}-\mathrm{HUE}$ &.$[38$ & .512 & 1.08 & 516 & 22.6 & 25.93 & 20.92 \\
\hline 45 G-HUE & .123 & .466 & 1.13 & 494 & 13.6 & 16.47 & 12.15 \\
\hline 115 G-EX & .126 & .477 & 1.10 & 496 & 14.7 & 17.58 & 13.25 \\
\hline $242 \mathrm{G}-\mathrm{S} 2$ & .150 & .475 & 0.78 & 496 & 8.9 & 10.13 & 8.26 \\
\hline $48 \mathrm{G}-\mathrm{T} 3$ & .154 & .476 & 0.73 & 496 & 38.6 & 43.60 & 36.08 \\
\hline $54 \mathrm{GC}-\mathrm{T} 4$ & .162 & .465 & 0.63 & 492 & 47.7 & 53.35 & 44.80 \\
\hline 247 G-P3-I & .176 & .473 & 0.44 & 495 & 16.0 & 17.27 & 15.35 \\
\hline \multicolumn{8}{|l|}{ Blues } \\
\hline 65 BC-HUE & .119 & .330 & 2.17 & 580 & 9.4 & 12.78 & 7.65 \\
\hline 276 B-S2 & .153 & .370 & 1.50 & 580 & 4.8 & 5.83 & 4.32 \\
\hline $57 \mathrm{BG}-\mathrm{T} 2$ & .139 & .430 & 1.06 & 591 & 30.9 & 36.99 & 27.83 \\
\hline \multicolumn{8}{|l|}{ Purples } \\
\hline $87 \mathrm{~V}$-HUE & .222 & .373 & 1.27 & 569 & 5.4 & 5.40 & 5.41 \\
\hline 289 RVPl-1 & .225 & .423 & 0.64 & 566 & 12.9 & 12.59 & 13.05 \\
\hline
\end{tabular}

Note. $\lambda_{\mathrm{D}}=$ Dominant wavelength: $\mathrm{R}=$ Standard reflectance; Rprot = Protanope reflectance; Rdeut = Deuteranope reflectance. 
Results

As in pilot studies, control subjects only committed a minimum number of erroneons denominations. Thereforc. specific information about their responses will not be offered and the description of results will focus on the dichromat macular responses. Table 3 shows. for protanopes $(n=12)$ and deuteranopes $(n=18)$, the number of responses that every busic chromatic calegory received in response to every tile. Deuteranope responses are presented in brackets. According to Model 1, there are two types of expected responses. One (numbers on gray background) indicates a correct-category response; the other (underlined numbers) indicates an incorrect-category response to a specific tile, as predicted by Mode! 1. The results from Table 3 were analysed in four different ways.

First, for every tile, the number of correct responses was compared with that expected from the equiprobabilistic use of Model 1, which depends on the number of earegories predicted. For example, Model 1 predicts green (correct response), yellow, orange, pink, and gray for tile number 36. Equiprobabilistic use of these categories should produce only $20 \%$ of correct responses or, in frequency terms. 2,4 correct responses (for analysis, we rounded off to the higher value, 3). Using at $X^{2}$ test, we found that the number of correct responses given by protanopes (11) was signilicantly higher than predicted by Model 1 for tile 36. In Table 3, asterisks indicate when correct response frequencies were higher than those predicted by Model I ( $\mathrm{p}<.05$, one (ail).

Second, the number of correct responses in control and color-blind observers was compared. Table 4 shows that when ati stimuli were grouped (A) ind when the analysis was restrictcd to the three chromitic categories (B), both dichromat groups made significantly more errors than controls. Talbe 4 also show's that protanopes made more crors than deuteranopes (except for one case, all differences were significant).

Third, the number of correct responses was andyzed as a function of the saturation level for every type of stimuli (greens, blacs, and purples) and of the kind of macular dichromat observer (protanopes and deuteranopes). Table 5 shows the errors mode by both dichromatic groups for every chromatic catcgory. Table 6 shows the results of applying a series of $x^{2}$ lests to evaluate whether crrors decreased significantly with the CIEu'v' saturation increment in every basic category. All the significant differences obtained correspond to a higher number of errors for less saturated stimuli.

Table 3

Response Matrix for Protanopes and Deuteranopes

\begin{tabular}{|c|c|c|c|c|c|c|c|c|c|c|c|}
\hline \multirow{2}{*}{$\begin{array}{l}\text { Presented } \\
\text { Tile }\end{array}$} & \multicolumn{11}{|c|}{ Response } \\
\hline & Green & Blue & Purple & Red & Yellow & Orange & Browls & l'ink & Gray & Blitck & White \\
\hline $36 \mathrm{Ygc}-\mathrm{HUUE}$ & $11 *\left(18^{*}\right)$ & & & & I & 001 & $10 !$ & 060 & $\underline{0(0)}$ & & \\
\hline $45 \mathrm{G}-\mathrm{HUE}$ & $11^{*}\left(18^{*}\right)$ & $0(0)$ & $(0)$ & & & & 1 & $\underline{0}$ & $\underline{0(0)}$ & & \\
\hline $115 \mathrm{G}-\mathrm{EX}$ & $12^{*}\left(17^{*}\right)$ & $0)$ & $(0)$ & & & $\underline{0}$ & ! & $\underline{0}$ & $0(0)$ & (1) & \\
\hline $48 \mathrm{G}-\mathrm{T} 3$ & $11 *(17 *)$ & 000 & & & ! & 9 & (1) & 009 & 0 & & \\
\hline $242 \mathrm{G}-\mathrm{S} 2$ & $6\left(16^{*}\right)$ & & (1) & & & & $\underline{3}$ & 1 & & $2(1)$ & \\
\hline 247 G-P3-1 & $9^{*}\left(16^{*}\right)$ & $(0)$ & (0) & & & & $\underline{2(0)}$ & O & $\underline{0(2)}$ & 1 & \\
\hline $54 \mathrm{GC}-14$ & $6\left(13^{*}\right)$ & & & & I & & (1) & 121 & $\underline{1(2)}$ & & $\underline{3}$ \\
\hline 65 BC-HUE & & $11^{*}\left(17^{*}\right)$ & $\underline{10}$ & 0 & & & 0 & & & & \\
\hline 276 B3-S2 & & $6\left(10^{*}\right)$ & $5(8)$ & & & & & 1 & & & \\
\hline $57 \mathrm{BG}-\mathrm{T} 2$ & $3(5)$ & $4\left(11^{*}\right)$ & $\underline{L(0)}$ & & & & & $\underline{10}$ & $\underline{3}(1)$ & (1) & \\
\hline $87 \mathrm{~V}-\mathrm{HUE}$ & (1) & $5(7)$ & $7 *\left(10^{*}\right)$ & $\underline{Q}(1)$ & & & $0(1)$ & $(2)$ & & (1) & \\
\hline 289 RVPl-I & $(0)$ & $5(1)$ & $1(12 *)$ & $\underline{0}$ & & & $\underline{0}$ & 4 & 1 & 1 & \\
\hline
\end{tabular}

Note. Numbers in gray rectangles represent the frequency of correct responses for the green (upper), biue (middle), and purple (lower) tiles. An asterisk indicates a frequency of correct responses statjstically highter $(p<05$ ) than predicted by Model I. Numbers in brackets correspond to deuteranope responses. Numbers with no brackets cortespond to protatnope responses. Underlined numbers indicate expected errors. Zero represents a category of expected errors that dici not occur. 
Titble 4

Results of Statistical Comparixoms between the Number of Correct Responses Obtained for the Various Observer Groups with the Different Stimuli Types

Groups compared $\quad x^{2}$

A. NI stimuli considered

Protanopes vs. Deuteranopes
Protanopes vs. Control
Deuteranopes vs. Control

$[0.432 *:$

$107.045^{* * *}$

$51.960 \%$

B. Grouped by chrontatic eategory

$\begin{array}{llr}\text { Green } & \text { Protanopes vs. Deutcranopes } & 10.432^{* * *} \\ & \text { Protanopes vs. Control } & 42.126^{* *} \\ \text { Blue } & \text { Deuteranopes vs. Control } & 15.01^{* * k} \\ & \text { Protanopes vs. Deuteranopes } & 1.386 \\ & \text { Protanopes vs. Control } & 24.128^{* * *} \\ \text { Purple } & \text { Deuteranopes vs. Control } & 14.993^{* *} \\ & \text { Protanopes vs. Deuteranopes } & 4.444^{* *} \\ & \text { Protanopes vs. Control } & 48.040^{* * *} \\ & \text { Deuteranopes vs, Contro] } & 26.503^{* *}\end{array}$

Note, $A=$ comparisons grouping the responses of all stimuli. $B=$ grouping only the responses given to the tiles of the same chromatic category.

$* p<.05 . * 2 p<.01$

Table 5

Namber of Errors for Protanopes and Deuteranopes as a Function of Stimuli Chromatic Category and Saturation Level

\begin{tabular}{|c|c|c|c|c|c|c|c|c|}
\hline & \multicolumn{8}{|c|}{ Stimuli type } \\
\hline & $\begin{array}{c}\text { Prototype } \\
\text { Gireen }\end{array}$ & $\begin{array}{c}\text { Satured } \\
\text { Green }\end{array}$ & $\begin{array}{c}\text { Meủium } \\
\text { Green }\end{array}$ & $\begin{array}{c}\text { Low } \\
\text { Cireell }\end{array}$ & $\begin{array}{l}\text { Satured } \\
\text { Blue }\end{array}$ & $\begin{array}{l}\text { I.ow } \\
\text { Bluc }\end{array}$ & $\begin{array}{c}\text { Satured } \\
\text { Purple }\end{array}$ & $\begin{array}{l}\text { Low } \\
\text { Purple }\end{array}$ \\
\hline Tiles & (36) & $(45+115)$ & $(48+242)$ & $(54+247)$ & $(65)$ & $(57+276)$ & $(87)$ & $(289)$ \\
\hline Protanopes & $\begin{array}{c}1 / 12 \\
(8.3 \%)\end{array}$ & $\begin{array}{c}1 / 24 \\
(4.1 \%)\end{array}$ & $\begin{array}{c}7 / 24 \\
(21.1 \%)\end{array}$ & $\begin{array}{c}9 / 24 \\
(37.5 \%)\end{array}$ & $\begin{array}{c}1 / 12 \\
(8.3 \%)\end{array}$ & $\begin{array}{c}14 / 24 \\
(58.3 \%)\end{array}$ & $\begin{array}{c}5 / 12 \\
(41.7 \%)\end{array}$ & $\begin{array}{c}11 / 12 \\
(91.7 \%)\end{array}$ \\
\hline Deuteranopes & $\begin{array}{l}0 / 18 \\
(0 \%)\end{array}$ & $\begin{array}{c}1 / 36 \\
(2.7 \%)\end{array}$ & $\begin{array}{c}3 / 36 \\
(8.3 \%)\end{array}$ & $\begin{array}{c}7 / 36 \\
(19.4 \%)\end{array}$ & $\begin{array}{c}1 / 18 \\
(5.5 \%)\end{array}$ & $\begin{array}{c}15 / 36 \\
(41.7 \%)\end{array}$ & $\begin{array}{c}8 / 18 \\
(44.4 \%)\end{array}$ & $\begin{array}{c}6 / 18 \\
(33.3 \%)\end{array}$ \\
\hline
\end{tabular}

Note: Underined numbers in bold type correspond to COLOR-AID identitication tiles. Ln fractions, the denominator represents the maximum number of possible errors.

Table 6

Results of Comparing, in each Chromatic Category. the Frequency of Errors of the Stimuli Groups Described in Table 5

\begin{tabular}{llc}
\hline Comparison & Protanopes & Deuteranopes \\
\hline Prototype green vs. Saturated green & 0.256 & $x^{2}$ \\
Saturated green vs. Medium green & $5.400^{*}$ & 0.509 \\
Saturated green vs. Low green & $8.084^{* *}$ & 1.059 \\
Medium green vs. Low green & 0.375 & $5.063^{*}$ \\
Saturated bive vs. Low blue & $8.229^{* *}$ & 1.858 \\
Saturated putple vs. Low purple & $6.750^{* *}$ & $7.505^{* *}$ \\
\hline
\end{tabular}

$* p<.05 . * *<<.01$. 
Table 7

Results of Statistical Comparisons between the Number of Expected and Unexpected Errors Obtained in the Three Groups of Color-Btind Observers: Total (Protanopes + Deateranopes), Protanopes, and Deureranopes

\begin{tabular}{|c|c|c|}
\hline & Groups compared & $x^{2}$ \\
\hline \multicolumn{3}{|c|}{ A. All stimuli considered } \\
\hline & Total (protanopes + deuteranopes) & $24.206^{* * *}$ \\
\hline & Protanopes & $9.949 * *$ \\
\hline & Deuteranopes & $12.947^{* * * *}$ \\
\hline \multicolumn{3}{|c|}{ B. Stimuli grouped by chromatic category. } \\
\hline \multirow[t]{3}{*}{ Green } & Total (prolanopes + deuteranopes) & $5,526^{*}$ \\
\hline & Protanopes & $3.010^{*}$ \\
\hline & Deuteranopes & 2.561 \\
\hline \multirow[t]{3}{*}{ Blue } & Total (protanopes + deuteranopes) & $12.155^{* * *}$ \\
\hline & Protanopes & $7.056^{*} *$ \\
\hline & Deuteranopes & $5.236^{*}$ \\
\hline \multirow[t]{3}{*}{ Purple } & Total (protanopes + deuteranopes) & $7.500^{\text {rk*t }}$ \\
\hline & Protanopes & $5.236^{*}$ \\
\hline & Deuteranopes & 2.489 \\
\hline
\end{tabular}

$* p<.05 . * * p<.01$.

Given the reduced number of errors, incorrect responses to all tiles were grouped for the last analysis. Table 7 shows that the more frequent errors corresponded to those predicted by Model 1, specially when protanopes where considered. This same result was also found when only responses to each chromatic category were considered.

\section{Discussion}

The results show that children diagnosed as dichromats perform more accurately than is predicted for a pure dichromat. This is especially true for high saturation stimuli. On the other hand, whereas low saturation stimuli increased naming etrors for both clinical groups, this increase was significantly higher for protanopes. These results also confirm that macular dichromats tend to correctly name saturated greens.

The most parsimonious interpretation of our results is similar to that proposed by Montag (1994) and assumes that diagnosed dichromats only behave like true dichromats in response to small-sized stimuli that project exclusively onto the macula. However, when stimuli also project onto the periphery, these same observers become anomalous trichromats and show partial functionality of their red-green mechanism, presumably because of the information provided for the cone type that is absent in macula but that could be present in peripheral retina. The increase of errors produced by reduced saturation and the fact that most of them were predictable from Model 2 are consistent with this explanation.
An alternative explanation would postulate that the anomalous dichromalism observed in macular dichromats would depend, partially or totally, on the inlormation provided by the rods in the retina. This explanation could only be fully discarded if a study were carried out in which the response of these photoreceptors was saturated by the stimulation intensity, thus annulling their informative ability. Although the illuminances employed in this study (250-400) lux) almost achieve this eftect (see, for example. Hood \& Finkelstein, 1986, Table 5.1), higher values should have been used in order to reject definitely any explanation of the results based on rod activity. Nevertheless, with regard to alternative explanations, those derived from the recent discovery of delectable differences within the same type of cone (Neitz. \& Neitz, 1998) should not be discarded. That is, contrary to prior assumptions by the scientific community, there arc small differences in the spectral sensitivities of the same type of cones (for example, protocones or deuteracones). At least theoretically, this variability may contribute to compensating for the loss of a cone type that characterizes macular dichromats.

As mentioned previously, our group's work is highly related to that of Montag (1994; Montag \& Boynton, 1989). In both cases, a naming lask of chromatic samples was used, and. more important, better-than-expected results were obtained in observers with only two types of cones in their retina. Nevertheless, Montag and our research group used the data in signilicantly different ways. In Montag's work, following the tradition of Boynton and Olson (1987), the names provided by the color-blind were used to calculate 
the position of the centroids of each of the 11 basic categories and, based on the comparison with common observers' categories, the authors were able to make deductions about the perceptive causes of the crrors (a weakness in the response capacity of the red-green mechanism). However, no effort was made to makc specific predictions about the identity of the naming errors (whose basic category, in fact, is used incorrectly for a specific sample). In an attempt to predict these naming errors, we undertook the present study, thus developing what has been called Model 2 .

The main implication of our results is that, like Montag (1994; Montag \& Boyton, 1989), they challenge an eminent idca that has pervaded many related fields of visual perception: that the visual response produced by mediumor large-sized stimuli is similar to that produced by small stimuli projected onto the macular retina. This idea underlies contemporary photometry, for example, although it is currently receiving much criticism in this area (Fotios \& Levermore, 1997; Lynes, 1996). This idea is also essential to what we have called Model I, which postulated that smallfield dichromats will still be dichromats even with largesized stimuli (i.e, most everyday stimuli). According to the results from the last thirty years (e.g., Montag, 1994; Nagy, 1980; Scheibner \& Boynton, 1968; Smith \& Pokomy, 1977), the high rate of correct denominations by macular dichromats that we observed would never have been predicted under the assumption of a pure dichromatic retina.

If there is so much evidence against it, what fate awaits Model 1 ? It will probably still be considered an appropriate model in specific contexts because it accurately accounts for functional vision with small-sized stimuli. For example, it has been successfully used to predict which backgrounds would make reading color-letter messages more difficult (Lilio, Collado, Martín, \& García, 1999). In this task, as in most reading tasks, the essential aspect was the way in which small contours are distinguished from their background. For this task, no help can be expected from peripheral cones and, consequently, Model 1 is accurate. It is also accurate to predict naming errors in smail-sized stimuli (Paramei, Bimler, \& Cavonious, 1998). Moreover, this model has dominated scientific thought on visual perception for most of this century and due to this, it is described as being accurate in general books on perception (see, for cxample, Coren, Ward, \& Enns, 1994), in publications that are directly related to standard evaluation of chromatic alteration (sce, for example, Birch, 1993; Lillo, 1996), and in guidelines to help the color-blind (e.g., Rigden, 1999).

Model 2 incorporates the predictions made by Model 1 , as far as the processing of small-sized stimuli is concerned, but assumes that, as more peripheral stimulation is involved, the more will peripheral cones, similar to the one missing from the macula, contribute to the visual response. From this framework, pseudoisochromaticity lines can be used to predict which categorics are expectable as erroneous responses, but will only predict error frequency when small- sized stimuli are used. Error reduction is predicted when large-sized and very saturated stimuli are projected onto the retina, as in our experiment. However, additional research is necded before a more quantitative relation between stimulus size and response accuracy can be established. In order to adapt the model to the characteristics of Spanish speakers as much as possible, basic research should be carried out to determine the exact basic Spanish category volumes. Thus, in our model, the volumes determined from Boynton and Olson's (1987) results can be substituted by other volumes, more specific to the Spanish population.

\section{References}

Abramov, I., Gordon, J., \& Chan, H. (1991). Color appearance across the retina: Effects of stimulus size. Journal of the Optical Society of America, 8, 404-414.

Alpern, M., \& Torii, S. (1968a). The luminosity curve of the protanomalus fovea. Journal of General Physiology, 52, 717737.

Alpern, M., \& Torii, S. (1968b). The luminosity curve of the deuteranomalous fovea. Joumal of General Physiology, 52, 738-749.

Berlin, B., \& Kay, P. (1969). Basic color terms: Their universality and evolurion. Berkeley, CA: University of California Press.

Birch, J. (1993). Diagnosis of defective color vision. Oxford, UK: Oxford University Press.

Boynton, R.M., \& Scheibner, H.M.O. (1967). On the perception of red by red-blind observers. Acta Chromatic, 1, 205-220.

Boynton, R.M., \& Olson, C.X. (1987). Locating basic colors in the OSA space. Color Research and Application, 12, 94-105.

Boynton, R.M., \& Olson, C.X. (1990). Salience of chromatic basic color terms confirmed by three measures. Vision Research, 30 , $1311-1317$.

Commission Internationale de l'Eclaiage (1931). CIE proceedings 1931. Cambridge, UK: Cambridge University Press.

Corbett, G.G., \& Davies, I.R.L. (1997). Establishing basic color terms: Measures and techniques. In C.L. Hardin \& L. Maffi (Eds.), Color categories in thought and language (pp. 197. 223). Cambridge, MA: Cambridge University Press.

Coren, S., Ward, L., \& Enns, J.T. (1994). Sensation and perception ( $4^{\text {th }}$ ed.). London: Harcourt Brace.

Crawford, T.D. (1982). Defining "basic colour terms." Anthroplogical Linguistics, 24, 338-343.

Ditvjes, I.R.L., \& Corbett, G.G. (1994). The basic color terms of Russian. Linguistics, 32, 65-89.

De Marco, P., Pokorny, J., \& Smith, V.C. (1992). Full-spectrum cone sensitivity functions for $\mathrm{X}$-chromosome-linked anomalous trichromats. Joumal of the Optical Society of America, 9, 1465. 1476 .

Fletcher, R. (1980). The City University Colour Vision Test $\left(2^{\text {nd }}\right.$ ed.). London: Keeler.

Fletcher, R., \& Voke, J. (1985). Defective colour vision. Bijstol,UK: Adam Hilger. 
Fotios, S., \& Levermore. G.J. (1997). Perception of electric light sources of different colour properties. Lighting Research and Techoologi: 29, 161-171.

Frome. F., Piantanida, T., \& Kelly. D.H. (1982). Psychophysical evidence for more than two cone types in dichromatic colour blindness. Sitence, 215, 417-419.

Hård, A., Sivick, L., \& Tonnquist, G. (1996). NCS, Natural colour system: From concept to research and applications. Part 1. Colour Research and Application. 21, 180-205.

Heath. G.G. (1958). Luminosity curves of normal and dicromatic observers. Science. 128. 775-776.

Hood, D.C.. \& Finkelstein. M.A. (1986). Sensitivity to light. In K.R. Boff, LL. Kaufman, \& J.P. Thomas (Eds.). Handhook of perception and haman performance. (Vol. 1, chap. 5, pp. 166). New York: Wilcy.

Hunt, R.W.G. (1987). Mecrsuring color: New York: Wilcy.

Kaiser, P.K., \& Boynton, R.M. (1996). Human color vision (2nt ed.). Washington, DC: Optical Socicty of America.

Kay, P. \& McDaniel, C.K. (1978). The linguistic significance of the meanings of basic colour terms. Langmage, 54, 610-646.

Kinnear. P.R. (1986). Spectral sensitivity for observers with protanomalous, extreme protanomalous and protanopic colour vision. Ophtalmic and Phwiological Optics. 0. 197-200.

Lillo, J. (1996). Manual del Test de Identificación de Daltonismos (TIDA). Madrid: TEA.

Lillo. J. (2000). Ergonomiat evaluacion y dixeño del ontono visible. Madrid: Alianza.

Lillo, J., Collado. J. Martín, J., \& Garcíat, Y. (1999). A fast and easy psycho-physical procedure to adjust luminance and achromatic contrast in conventional video display terminals (VDT). In D. Hatris ([icl), Engineering parchology and cognitine crgonomics: Wol. 4. Job design, product design and hwmancomputer interaction (pp. 131-140). Ashgate. UK: Aldershot.

Lillo, J.. Collado, J., Vitini, 1., Ponte, E., \& Sánchez, M.P. (1998). Detección de daltonismos tipo protán utilizando un monitor de televisión convencional. Psicothenta, 10, 447-457.

Lillo, J., Davies, I.R.L., Vitin, I., \& Caballero, A. (1999). Macular dichromats' chromatic space: Basic categories and partial asymmetrics. Perception. 28.66.

Lillo, J., Davies, I. Collado, J., Ponte, E., \& Vitini, I. (in press). Colour naming by colour-blind children. Journat of child language

Lynes, J.A. (1996). Daylight and photometric anomalies. Lighing Resewh and Techology, 28, 63-67.

Montag, E.D. (1994). Surface color namiog in dichtomats. Vision Research, 34, 2137-2151.
Montay. E.D.. \& Boynton. R.M. (1987). Rod influence in dichromatic sufface color pereeption. Viwom Researh. 27 . 2153-2162.

Nagy, A.L. (1980). Litrge-field color matches of dichromats. Jormal of the Oprical Societr of America. 70. 778-784.

Nagy, A.L., \& Boyntom. R.M. (1979). Large-field color naming of dichromats with rods bleached. Jomal of the Opical Soctery of Amerira, 69, 1259-1265.

Nary. A.L., \& Doyal. J.A. (1993). Red-green color discrimination als a function of stimulus ficld size in peripheral vision. Jomoral of the Optical Society of America, 10. 1147-1156.

Neits. M. \& Neit. J. (1998). Molecular genetics and the bological basis of colular vision, ln W. Backhaus. R. Kliegl, \& J.S. Wener (Eis.). Colon vision: Perspectives from different disciplines (p). 301-318). Berlin: Gruyter.

Paramei, G.V., Bimler, D.L., \& Cavonious, R. (1998). Elfect of luminance on color pereeption of protanopes. Visiom Research, $38,3397-3401$

Pitt, F.H.G. (1935). Chancteristics of dichromatic vision, with an appendix on anomalous trichromatic vision. Great Britain Medical Resend Conmell Special Repont Series. No 200.

Rigden, C. (1999). "The eye of the beholder" - Designing for colour-blind users. British Tetecommunicatons Engineering. 17, 2-6.

Scheibner, H.M.O., \& Boynton. R.M. (1968). Residual red-green discrimination in dichromats. Journal of the Optical Sociefy of America. 58, 1151-1158.

Smith, V... \& Pokomy, J. (1975). Spectral sensitivity of the foveal cone photopigments between 400 and $500 \mathrm{~nm}$. Vision Research. $15,101-171$.

Sinith. V.C. \& Pokorny, I. (1977). Large-field trichromacy in protanopes and deuteranopes. Jommal of the Optical Society of America, 67. 213-220.

Travis, D. (1991). Effective color displaw: Theory and pracfice. London: Academic Press.

Sturges, J., \& Whitfield. A. (1997). Salient features of Munsell colour space as a function of monolexemic naming and response latencies. Vision Resardh, 37, 307-313.

Wyszecki, G. (1986). Color Appearance. In K.R. Boff, l.L. Kaudman, \& J.P. Thomas (Eds.), Handlbook of perception and human performance. (Vol. 1, chap. 9. pp. 1-57). New York: Wiley.

Received April 22, 1999

Revision received June 5, 2000 Accepted October 6, 2000) 